\title{
Iatrogenic esophageal rupture due to anterior cervical spine surgery
}

Kalliopi Athanassiadi ${ }^{*}$, Moschos Fratzoglou ${ }^{2}$, Dimosthenis Xenis ${ }^{3}$, Stamatia Pispirigkou ${ }^{1}$, Evangelos Papadopoulos ${ }^{2}$ and Athanassios Rogdakis ${ }^{1}$

${ }^{1}$ Departments of Thoracic Surgery, General Hospital of Piraeus, Athens, Greece

${ }^{2}$ Departments of Neurosurgery, General Hospital of Piraeus, Athens, Greece

${ }^{3}$ Departments of Radiology, General Hospital of Piraeus, Athens,

\begin{abstract}
Anterior cervical corpectomy from $\mathrm{C} 2-\mathrm{T} 1$ is being used to decompress and reconstruct the cervical spine for a wide variety of degenerative disorders, trauma, neoplasms, and infectious disorders or as a salvage surgery for correcting kyphotic deformities and vertebral collapse. The technique minimally disrupts normal cervical muscles and is associated with a low risk of injuring surrounding structures such as esophagus. A case of an iatrogenic esophageal wall perforation subsequent to cervical corpectomy through an anterior approach along with a review of the literature and an algorithm of treatment are presented.

A 52-year-old, emphysematous man underwent anterior cervical stabilization using plate and screw for vertebral collapse of the C5 vertebra followed by a huge cervicofacial subcutaneous emphysema on the $1^{\text {st }}$ postoperative day. A cervical and chest CT was performed and revealed a rupture of esophagus at the site of the plate. The rupture was also confirmed by an esophagogram. The patient was led directly to surgery. During the procedure, the implant was in place, but a large defect was found along the posterior wall of the cervical part of the esophagus. The patient underwent wide drainage of the prevertebral space, direct repair of the defect of the esophagus with separate sutures and formation of a pedicle flap with sternocleidomastoideus and infrahyoid muscles leaving the osteosynthetic plate in place. Postoperatively he developed respiratory insufficiency and stayed intubated for 10 days in the ICU under antibiotic treatment. After a hospitalization of 24 days he was discharged and in a follow up of 6 months there was no recurrence.
\end{abstract}

In conclusion, esophageal perforation during cervical spine surgery is an uncommon occurrence that can be potentially life threatening. Early recognition of the injury followed by appropriate therapy individualized on a case-by- case basis with or without removal of the foreign material is likely to lead to successful resolution of symptoms, thus minimizing long-term morbidity and mortality.

\section{Introduction}

Cervical corpectomy from C2-T1 through an anterior approach is being used to decompress and reconstruct the cervical spine for a wide variety of degenerative disorders [1-3], trauma [3-5], neoplasms $[5,6]$, and infectious disorders $[7,8]$, and as a salvage surgery for correcting kyphotic deformities or vertebral collapse [9] in patients who have undergone posterior decompressive laminectomy $[9,10]$. In degenerative disease the indication for corpectomy is compression that extends beyond the disc space behind the vertebral body. In such cases, performing corpectomy is essential to achieve adequate spinal cord decompression. Followed by reconstruction, cervical corpectomy permits the most direct and adequate decompression of the spinal cord or resection of lesions that involve the cervical vertebrae [11]. Dissection of normal cervical muscles is normally associated with a low risk of injuring surrounding structures.

Esophageal perforation is a recognized potentially fatal complication of anterior cervical spine surgery and may be the result of fracture, difficult surgical exposure/retraction, or instrumentation placement, but has only been documented in the literature by case reports and case series [12-23]. This complication is implicated in less than $2 \%$ of all anterior cervical spinal cases [12-23]. The management of this complication is controversial and often case specific.

We describe a case of an iatrogenic esophageal wall perforation subsequent to cervical corpectomy through an anterior approach because of its complicated clinical course as well as its successful outcome without the removal of the foreign material. A limited review of the literature is presented, and an algorithm of treatment is suggested.

\section{Case report}

A 52-year-old man suffering from severe emphysema was admitted to our hospital due to degenerative spondylosis for anterior spinal decompression at the level C5-C6. Under general anaesthesia, a rightsided approach was undertaken through an oblique vertical incision made along the anterior border of the sternocleidomastoid muscle in order to get a longer exposure. The level of the disease was reconfirmed by intraoperative radiography. The anterior longitudinal ligament was incised, and the necessary corpectomy was performed so that the spinal cord was decompressed. Finally, cervical stabilization by using an osteosynthetic plate for vertebral collapse of the C5 vertebra was done and a lateral cervical radiograph was obtained to check the position.

*Correspondence to: Kalliopi Athanassiadi, Departments of Thoracic Surgery, General Hospital of Piraeus, Athens, Greece, Tel: +30 213208 1000; E-mail: kallatha@otenet.gr

Key words: iatrogenic esophageal perforation, spine surgery, anterior approach

Received: September 01, 2020; Accepted: September 21, 2020; Published: September 24, 2020 
On the $1^{\text {st }}$ postoperative day, the patient presented a huge cervicofacial subcutaneous emphysema and was referred to our department. A cervical and chest CT were performed and revealed a huge subcutaneous emphysema and a possible rupture of the esophagus (Figure 1). Then the rupture was confirmed by an esophagogram (Figure 2). There was no sepsis due to the early esophageal perforation at the time of referral.

The patient was led directly to surgery and underwent initial neck exploration and debridement through a left cervical incision along the sternocleidomastoid muscle, the adjust structures were dissected and the esophagus was fully mobilized. A large defect of $3.7 \mathrm{~cm}$ was found at the posterior wall of the cervical esophagus. The patient underwent wide drainage of the prevertebral space and primary repair of the defect of the esophagus by using interrupted sutures (Figure 3). A pedicle flap of sternocleidomastoideus muscle along with a pedicled infrahyoid flap gave an excellent result. Both were transferred between the esophageal wall and the vertebrae covering the esophagus and isolating it in that way from the osteosynthetic plate that was checked and left in place. Finally, a closed-suction external drain was placed, and the wound was closed with interrupted sutures.

The patient developed respiratory failure due to severe aspiration pneumonia and was transferred to the ICU where he had stayed intubated and tracheostomised for 10 days under adequate antibiotic treatment. After a hospitalization of 24 days, he was discharged and the clinical follow up was otherwise uncomplicated, no dysphagia or dislocation of a screw was observed in a 6 months' period.

\section{Discussion and conclusion}

The anterior surgical approach for spinal repair, with or without the insertion of stabilizing hardware, is an established procedure in the management of cervical spine pathology. This approach seems to be superior to the posterior one, since it is considered safer and easier with improved rate of skeletal union, and without cervical musculature transection [11]. However, the anterior approach often requires dissection of the upper aerodigestive system and might lead to esophageal perforation [12,14-29]. Use of instrumentation, large grafts, trauma, and a history of esophageal disease or diverticula are potential

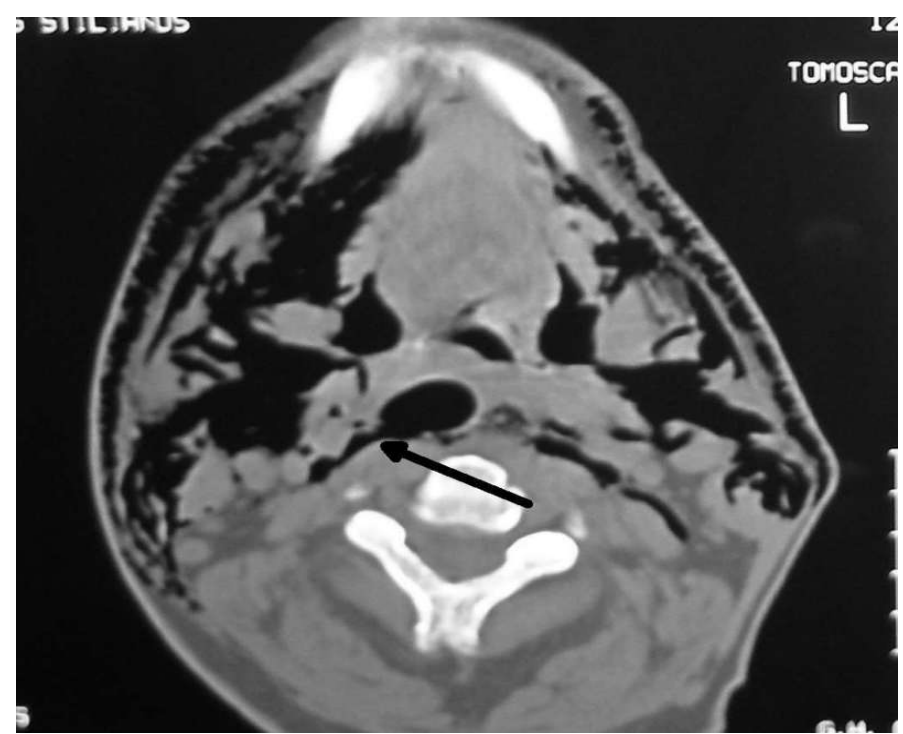

Figure 1. Cervical CT scan revealing subcutaneous emphysema and suggesting an esophageal rupture [arrow].

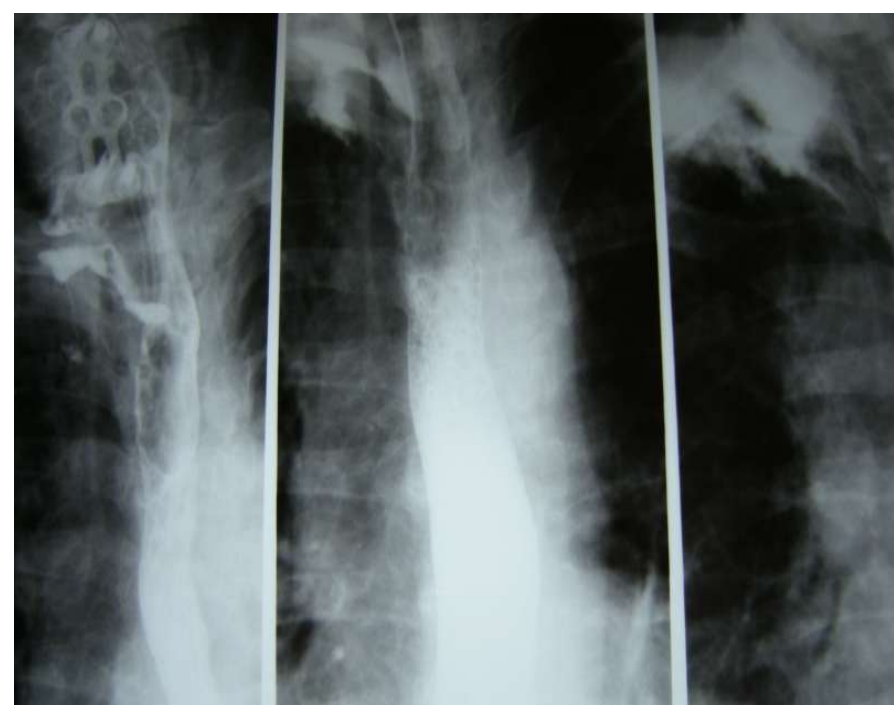

Figure 2. Esophagogram showing the site of rupre of the cervical esophagus.

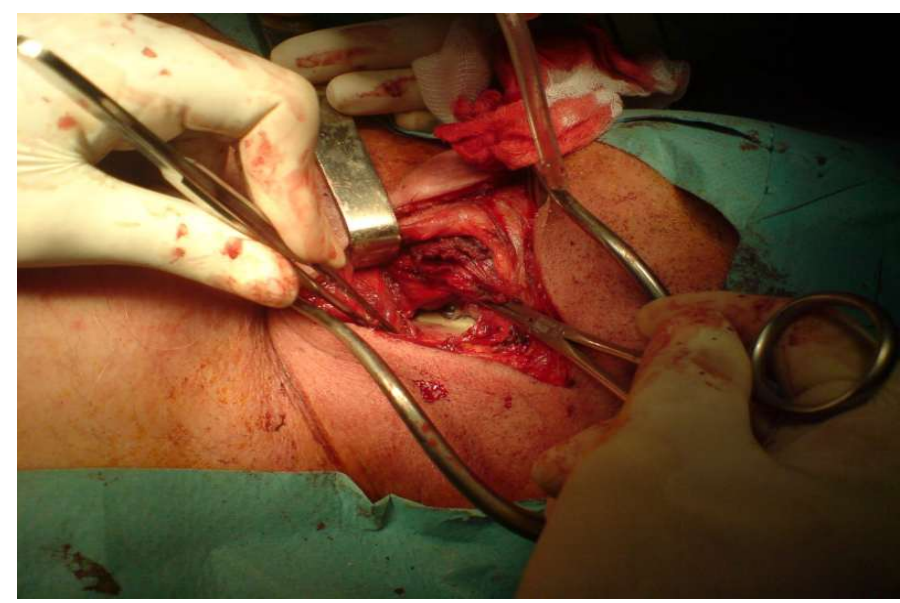

Figure 3. Intraoperative picture after suturing the esophagus leaving the osteosynthetic plate in place.

predisposing factors to an esophageal injury during anterior cervical spinal surgery [30].

The incidence of this complication ranges from $0.25 \%$ rate reported by the CSRS survey ${ }^{14}$ in 1989 to $2 \%$ with the majority of the studies having an incidence of less than $1 \%[11,16,21,30]$.

Early esophageal perforation is generally the result of intraoperative manipulation, becomes evident immediately or in the early postoperative course, while delayed esophageal perforation, more likely secondary to hardware erosion or migration can happen months to years after surgery.

It is well known from the anatomy of Lannier's triangle, formed by the constrictor pharyngeus and cricopharyngeus muscles at the C5 and C6 levels that the posterior esophageal mucosa is extremely thin, covered only by fascia. So, the risk of iatrogenous injury of the esophagus is really high and might increase in the presence of osteophytes and kyphosis [19]. One has to mention that different kind of retractors, sometimes sharp ones might also produce intraoperatively an esophageal injury. Another common etiology of esophageal injury is graft dislocation, while the incidence depends on the type of operation, for instance, it seems to be higher in corpectomy with increased rates 
of graft extrusion and/or instrumentation migration with esophageal or tracheal compromise resulting in occasional fatal outcomes [29-34].

The time of presentation ranges from $24 \mathrm{~h}$ to 10 years, characterized as acute within 24 hours, subacute after 24 hours, or delayed up to a reported 10 years. In the CSRS review, 6 perforations were recognized intraoperatively, 6 postoperatively, and the rest in weeks or months later [14]. The esophageal perforation in most cases in this literature review was identified postoperatively based on patients' symptoms, since one often misses the injury intraoperatively and symptoms start within the first 24 hours with dysphagia, odynophagia, aspiration, hoarseness and subcutaneous emphysema being the most common one in acute cases, while in subacute and delayed one's fever, cervical abscess, septicemia, mediastinitis and meningitis being present. In older series, it seems that this complication due the delay of diagnosis was underestimated or misdiagnosed. Once there is a suspicion, further evaluation is needed with barium/Gastrografin swallow or endoscopy. Imaging studies with plain films or simple CT scans can detect air around the plate.

The management of an esophageal perforation in the setting of spine surgery is challenging and starts with a prompt diagnosis. Delay in diagnosis and initiation of treatment can lead to high morbidity and mortality ranging from 20 to $50 \%$ [30]. A variety of surgical approaches have been reported in small case series or case reports [15,16,19-28] since the treatment of esophageal injury is highly case specific and depends on the time of diagnosis, on the present symptoms and on the size of laceration. In addition to broad spectrum intravenous antibiotics, several methods have been described to repair the perforation, which range from enteral tube feeding, direct repair, and/or repair with a local or free muscle flap $[14,22,23,25,26,29,30]$.

In cases of early diagnosis with small lacerations the treatment may be conservative with nasogastric tube placement and parenteral antibiotics. In larger defects, as it was in our case, primary repair by using interrupted sutures with or without tissue reinforcement is advisable, followed by nasogastric tube placement. Choice of soft tissue reinforcement includes omental, pectoral or sternocleidomastoid flaps $[22,23,25,26,29,30,33]$. We preferred a pedicled infrahyoid and sternocleidomastoid flap as both muscles are easy to mobilize between esophagus and spine.

In late esophageal perforations with larger lacerations and severe symptoms as mediastinitis and sepsis, different methods are reported such as re-exploration with plate removal, primary or/and reinforced tissue closure (e.g., sternocleidomastoid myoplasty), wound drainage (e.g., T-tube placement to provide a controlled esophagocutaneous fistula), or exclusion and diversion (end-cervical esophagostomy and gastrostomy) [16,23,25,29,30,33].

In the majority of cases published in the literature all foreign material was removed at the time of operation $[16,25,30]$. The authors decided to leave the osteosynthetic plate in place and no further infection occurred, since there was an intraoperative injury, and the diagnosis was made within the first 24 hours. An algorithm summarizing standardized management approach after anterior spinal surgery was published by Rueth et al. [25], in 2010. In our opinion, it can be modified in order to differentiate between early and delayed diagnosis and occult versus non occult perforations (Figure 4).

In conclusion, it has to be stressed that when encountering acute dysphagia or subcutaneous cervical emphysema after cervical spine surgery, one should think of an esophageal perforation and install immediate further diagnostics and therapy. Treatment depends on the time of detection and size of the defect. Early recognition of the injury followed by appropriate therapy individualized on a case-by- case basis is likely to lead to successful resolution of symptoms, thus minimizing long-term morbidity and mortality.

As in other complications prevention is the key word. To prevent such injury, care must be taken to identify and protect the esophagus intraoperatively and avoid technical mistakes and subsequent device failure.

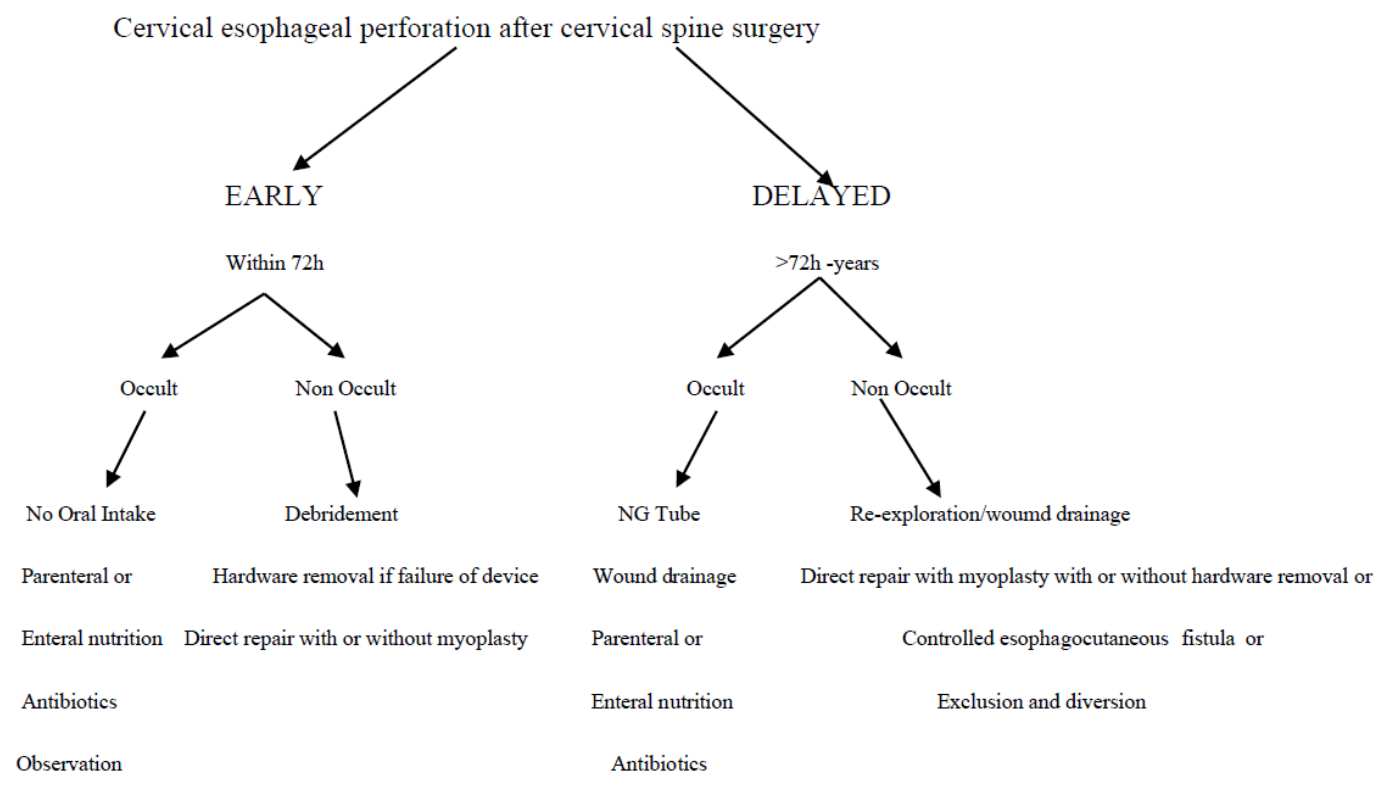

Hardware removal if failure of device

Observation

Figure 4. Algorithm proposed for cervical esophageal perforation after cervical spine surgery. 


\section{References}

1. Bohlman HH, Anderson PA (1992) Anterior decompression and arthrodesis of the cervical spine: long-term motor improvement: part I-improvement in incomplete traumatic quadriparesis. J Bone Joint Surg (Am) 74: 671-682. [Crossref]

2. Hu R, Wilber RG (1993) Anterior cervical corpectomy for the treatment of complex cervical lesions. Can J Surg 36: 85-88. [Crossref]

3. Seifert V, Stolke D (1991) Multisegmental cervical spondylosis: treatment by spondylectomy, microsurgical decompression, and osteosynthesis. Neurosurgery 29: 498-503. [Crossref]

4. Kostiuk JP, Connolly PJ, Esses SI, Suh P (1993) Anterior cervical plate fixation with the titanium hollow screw plate system. Spine 18: 1273-1278. [Crossref]

5. Levi L, Wolf A, Rigamonti D, Ragheb J, Mirvis S, et al. (1991) Anterior decompression in cervical spine trauma: does the timing of surgery affect the outcome? Neurosurgery 29: 216-222. [Crossref]

6. Cybulski GR (1989) Methods of surgical stabilization for stabilization for metastatic disease of the spine. Neurosurgery 25: 240-252. [Crossref]

7. Moore AJ, Uttley D (1989) Anterior decompression and stabilization of the spine in malignant disease. Neurosurgery 24: 713-717. [Crossref]

8. Sypert GW (1992) Anterior decompression and fusion for cervical myelopathy. Disorders of the Cervical Spine. Williams \& Wilkins. Baltimore, USA. pp: 407-416.

9. Herman JM, Sonntag VK (1994) Cervical corpectomy and plate fixation for postlaminectomy kyphosis. J Neurosurg 80: 963-970.

10. Caspar W, Barbier DD, Klara PM (1989) Anterior cervical fusion and Caspar plate stabilization for cervical trauma. Neurosurgery 25: 491-502. [Crossref]

11. Capen DA, Garland DE, Waters RL (1985) Surgical stabilization of the cervical spine. A comparative analysis of anterior and posterior spine fusions. Clin Orthop Relat Res 1985: 229-237. [Crossref]

12. Lamesch P, Dralle H, Blauth M, Hauss J, Meyer HJ (1997) Perforation of the cervical esophagus after ventral fusion of the cervical spine. Defect coverage by muscle-plasty with the sternocleidomastoid muscle: case report and review of the literature. Chirurg 68: 543-547. [Crossref]

13. Flynn TB (1982) Neurologic complications of anterior cervical interbody fusion. Spine 7: 536-539. [Crossref]

14. Newhouse KE, Lindsey RW, Clark CR, Lieponis J, Murphy MJ (1989) Esophageal perforation following anterior cervical spine surgery-CSRS survey. Spine 14: 10511053. [Crossref]

15. Graham JJ (1989) Complications of cervical spine surgery: a five-year report on a survey of the membership of the Cervical Spine Research Society by the Morbidity and Mortality Committee. Spine 14: 1046-1050. [Crossref]

16. Dakwar E, Uribe JS, Padhya TA, Vale FL (2009) Management of delayed esophageal perforations after anterior cervical spinal surgery. J Neurosurg Spine 11: 320-325. [Crossref]

17. Gaudinez RF, English GM, Gebhard JS, Brugman JL, Donaldson DH, et al. (2000) Esophageal perforations after anterior cervical surgery. J Spinal Disord 13: 77-84. [Crossref]
18. Wierzbicka M, Pabiszczak M, Smuszkiewicz P, Szyfter W (2005) Wide esophageal wall rupture as iatrogenic complication of anterior cervical spine surgery. Otolaryngol Pol 59: 887-892. [Crossref]

19. Tew Jr JM, Mayfield FH (1976) Complications of surgery of the anterior cervical spine. Clin Neurosurg 24: 424-434.

20. Yee GH, Terry AF (1993) Esophageal penetration by an anterior cervical fixation device. Spine 522-527.

21. Thomas JP, Finch R (1991) Esophageal erosion-a complication of acrylic fixation in anterior cervical fusion. Spine 16: 1238-1240. [Crossref]

22. Van Berge Henegouwen DP, Roukema JA, de Nie JC, vd Werken C (1991) Esophageal perforation during surgery on the cervical spine. Neurosurgery 29: 766-768. [Crossref]

23. Konstantakos AK, Temes RT (2005) Delayed Esophageal Perforation: A Complication of Anterior Cervical Spine Fixation. Ann Thorac Surg 80: 349. [Crossref]

24. Sahjpaul RL (2007) Esophageal perforation from anterior cervical screw migration. Surg Neurol 68: 205-210. [Crossref]

25. Rueth N, Shaw D, Groth S, Stranberg S, D'Cunha J, Sembrano J, et al. (2010) Management of cervical esophageal injury after spinal surgery. Ann Thorac Surg 90: 1128-1133. [Crossref]

26. Haku T, Okuda S, Kanematsu F, Oda T, Miyauchi A, et al. (2008) Repair of cervical esophageal perforation using longus colli muscle flap: a case report with cervical spinal cord injury. Spine J 8: 831-835.

27. Pichler W, Maier A, Rappl T, Clement HG, Grechenig W (2006) Delayed hypopharyngeal and esophageal perforation after anterior spinal fusion: primary repair reinforced by pedicled pectoralis major flap. Spine 31: E268-E270. [Crossref]

28. Pompili A, Canitano S, Caroli F, Caterino M, Crecco M, et al. (2002) Asymptomatic Esophageal Perforation Caused by Late Screw Migration After Anterior Cervical Plating: Report of a Case and Review of Relevant Literature. Spine 27: 499-502. [Crossref]

29. Reid RR, Dutra J, Conley DB, Ondra SL, Dumanian GA (2004) Improved repair of cervical esophageal fistula complicating anterior spinal fusion: free omental flap compared with pectoralis major flap. Report of four cases. J Neurosurg 100: S66-S70. [Crossref]

30. Patel NP, Putnam Wolcott W, Johnson JP, Cambron H, Lewin M, et al. (2008) Esophageal injury associated with anterior cervical spine surgery. Surg Neurol 69: 2024. [Crossref]

31. Foley KT, Smith MM, Wiles DA (1997) Anterior cervical plating does not prevent strut graft displacement in multilevel cervical corpectomy. Cervical Spine Research Society 25th Annual Meeting, Rancho Mirage, California, USA. Pp: 75.

32. Riew KD, Sethi NS, Devney J, Goette K, Choi K (1999) Complications of buttress plate stabilization of cervical corpectomy. Spine 24: 2404-2410. [Crossref]

33. Orlando ER, Caroli E, Ferrante L (2003) Management of the cervical esophagus and hypofarinx perforations complicating anterior spine surgery. Spine 28: E290-E295. [Crossref]

34. Vrouenraets BC, Been HD, Brouwer-Mladin R, Bruno M, van Lanschot JJ (2004) Esophageal perforation associated with cervical spine surgery: report of two cases and review of the literature. Dig Surg 21: 246-249. [Crossref]

Copyright: $(2020$ Athanassiadi K. This is an open-access article distributed under the terms of the Creative Commons Attribution License, which permits unrestricted use, distribution, and reproduction in any medium, provided the original author and source are credited. 